\title{
Bilayered Glass-Ceramics as Sealants for SOFCs
}

Stefanie Hauber ${ }^{1,3}$, Svenja Dittrich ${ }^{2,3}$, Tobias M. Walter ${ }^{2}$, Bernhard Durschang ${ }^{1}$, Karl G. Schell ${ }^{2}$, Ethel C. Bucharsky ${ }^{2}$, Elisabeth Reitz ${ }^{3}$,Gerhard Sextl ${ }^{1}$ and Michael J. Hoffmann ${ }^{2}$

1. Fraunhofer ISC, Würzburg 97082, Germany

2. Karlsruhe Institute of Technology IAM-KWT, Karlsruhe 76131, Germany

3. ElringKlinger AG, Dettingen an der Erms 72581, Germany

\begin{abstract}
Glass-ceramics are often used as sealants in solid oxide fuel cells (SOFC). But interfacing components, such as ferritic stainless steel and YSZ electrolyte, may vary in their requirements regarding sealing properties, especially in terms of thermal expansion. A bilayered glass-ceramic system was developed to overcome the mismatch in coefficients of thermal expansion (CTE) between ferritic steel and YSZ. Therefore, two different glass-ceramics with slightly different CTEs were developed, one with good bonding characteristics to the ferritic steel and the other to the YSZ electrolyte. Steel and electrolyte components were coated with a layer of their corresponding glass sealant paste and heated up to form a sandwich sample. During the heat treatment of the sealing process, the glasses are crystallized into glass-ceramics. The resulting interface between the two glass-ceramics is of special interest. Cross-sections of the sandwich samples were cut, polished and investigated using SEM. The glass-ceramics show continuous, gap-free layers and excellent bonding to both steel and YSZ. Energy release rates are measured for single and bilayered glass sealants by mechanical testing. The designed bilayered glass-ceramics fulfill the special requirements of ferritic steel and YSZ. They show excellent potential to become a new outstanding sealant for SOFCs.
\end{abstract}

Key words: SOFC, bilayered glass-ceramic sealant, screen-printing, Charalambides, crystallization.

\section{Introduction}

The reduction of greenhouse gases and harmful emissions is more relevant than ever. Recently, Germany and five other European countries were sued by the EU Commission for exceeding the nitrogen oxide limit values [1]. A significant contribution to cleaner air is provided by fuel cells. In particular, solid oxide fuel cells (SOFCs) provide an effective, noiseless and low emission alternative to, for example, conventional diesel generators [2, 3].

Compared to other fuel cells, which can only work with pure hydrogen as a fuel gas, SOFCs can also use hydrocarbons, such as e.g. biogas. Actually, SOFCs are mainly used as auxiliary power units for decentralized energy supply in both mobile and stationary applications, for example at the construction sites of pipelines and wind turbines or to

Corresponding author: Stefanie Hauber, M.Sc., master of science, research fields: glass-ceramics, SOFCs, power houses and boats. The special feature of SOFCs is the very high operating temperature between 750 and $1,000{ }^{\circ} \mathrm{C}$. These high temperatures represent the greatest challenge when it comes to the materials being used to build those fuel cells [2, 4-6].

One of the most critical parts in SOFCs is the sealant between interconnector and electrolyte. The interconnector is usually made of ferritic steel [7] while the oxygen permeable electrolyte consists of fully yttria-stabilized zirconia. There are a number of requirements that are placed on this sealant. It must have good adhesion to both steel and electrolyte and has to be gas-tight to prevent uncontrolled mixing of oxygen and fuel gas. The sealant should be electrically insulating in order to prevent short circuits. And probably the biggest challenge is a suitable coefficient of thermal expansion which at best lies between interconnector and electrolyte. In addition, temperature resistance of the sealant is important to withstand the high operating temperatures of the 
SOFC (between 750 and $1,000^{\circ} \mathrm{C}$ ) and thermal cycles which occur by turning the fuel cell on and off. A suitable material for the application as a sealant in SOFCs is a glass-ceramic. There is currently a great interest in the perfect single glass-ceramic that meets all those requirements [7, 8].

Instead of developing a single glass-ceramic that is reasonably adapted to both steel as well as electrolyte, two different glass-ceramics, one with good bonding properties to the steel and the other with good bonding to the electrolyte are developed and stacked together to a bilayered glass-ceramic sealant.

For characterizing the adhesion of glass-metal interfaces, a four-point-bending test after Charalambides [9], modified by Hofinger et al. [10], is used which is described in several studies [11-13]. It seems to be more reliable to measure the adhesion of layers on compact support than the pull-off method or the indentation method, which are applied on porous support [14]. Thus, the Charalambides test is a proper method for the mechanical characterization of a sandwich-sample of a single and bilayered glass-ceramic sealant.

\section{Experimental}

\subsection{Glass Preparation and Glass-Ceramics} Characterization

The two starting glasses contain approximately 20 $\mathrm{mol} \% \mathrm{MgO}, 10 \mathrm{~mol} \% \mathrm{CaO}, 10 \mathrm{~mol} \% \mathrm{~B}_{2} \mathrm{O}_{3}, 5 \mathrm{~mol} \%$ $\mathrm{Al}_{2} \mathrm{O}_{3}$ and $45 \mathrm{~mol} \% \quad \mathrm{SiO}_{2}$. Glass 2 additionally includes 6 mol\% $\quad \mathrm{ZrO}_{2}+\mathrm{Y}_{2} \mathrm{O}_{3}$. The glasses are prepared by melting a glass batch of the above mentioned oxides at about $1,500{ }^{\circ} \mathrm{C}$ in a Pt-Rh crucible. Subsequently, the melt is poured into cold water, resulting in the formation of a glass frit. The glass frit is then ground to powder in a planetary ball mill to achieve a $d_{50}$ particle size of 5-30 $\mu \mathrm{m}$. CTE measurements are carried out with a dilatometer (Netzsch Dil $402 \mathrm{C}$ ) from $25-500{ }^{\circ} \mathrm{C}$ in air. For this method, the ground glass powders are pressed into BN coated, cylindrical $\mathrm{Al}_{2} \mathrm{O}_{3}$ crucibles, heat-treated at
$900{ }^{\circ} \mathrm{C}$ for $2 \mathrm{~h}$ and then the obtained glass-ceramic bars are cut into samples of 25 mm length.

To analyze the sintering and flow behavior of the glasses, thermo-optical measurements were performed by a “Thermo-Optical Measurement” (Fraunhofer ISC TOM) device. This device consists of a furnace where the sample is heated and a light source, which irradiates the sample during the heating process. A camera collects shadow images of the sample, which can be recorded at certain intervals. The changes in shape of the glass-sample are in situ visible with this method. For those thermo-optical measurements, the glass powders were pressed in the form of pellets with the dimension of 9 to $10 \mathrm{~mm}$ in height and $21.25 \mathrm{~mm}$ in diameter after pre-pressing at $10 \mathrm{MPa}$ and subsequent isostatically cold pressing at $400 \mathrm{MPa}$.

\subsection{Screen-Printing and Joining of Bilayeredglass-Ceramic Sealants}

The glass powder is dispersed in a commercially available suspension medium (Zschimmer und Schwarz) to obtain a suitable screen-printing paste. A network former and a dispersing agent (BYK Additives \& Instruments) improve the flow properties, which are characterized by rheological measurements. For the deposition of glass-ceramic thick films, the screen-printing paste must exhibit a shear thinning behavior, which is identified by a reduction in viscosity at increasing shear rate. Furthermore, it is important that the paste completely regains its structure after the screen snap-off. This is examined by rheological measurements using a rotational rheometer (Haake Mars 60, Thermo Fisher) with plate-plate geometry (diameter $=35 \mathrm{~mm}$, gap $=500$ $\mu \mathrm{m})$. The viscosity curve is recorded at $20^{\circ} \mathrm{C}$ using a ramp test with a pre-shear of $10 \mathrm{~s}^{-1}$ for $1 \mathrm{~min}$; the shear rate is increased from 0.1 to $100 \mathrm{~s}^{-1}$ at constant stress. Shear jumping tests are measured at shear loadings comparable to the screen-printing process (a low shear rate of $0.1 \mathrm{~s}^{-1}$ and high shear rate of $100 \mathrm{~s}^{-1}$ are applied). Afterwards, the screen-printing paste is 
printed on ferritic steel substrates (Crofer 22H [15], 50 $\mathrm{mm} \times 50 \mathrm{~mm} \times 0.3 \mathrm{~mm}$ ) and 8YSZ electrolytes by a small lab screen-printing machine (SD 05 Roku Print) at low squeegee speed. A screen mesh size of $375 \mu \mathrm{m}$, a $5 \mathrm{~mm}$ snap off and a squeegee pressure of 5 bar were used. The optimized glass-ceramic paste is printed on the respective contact material, Glass 1 on ferritic steel and Glass 2 on YSZ electrolyte, and is dried for $30 \mathrm{~min}$ at $80^{\circ} \mathrm{C}$. The contact materials are stacked on top of each other in order to form a sandwich sample (Fig. 1).

The samples are placed in a furnace with an applied load of 30-120 kPa and heated up with $5 \mathrm{~K} / \mathrm{min}$ to a temperature of $450{ }^{\circ} \mathrm{C}$ to burn out the organic components of the glass paste. After a holding time of $0.5 \mathrm{~h}$ the sample is heated up again with $5 \mathrm{~K} / \mathrm{min}$ to the annealing temperature (between $860{ }^{\circ} \mathrm{C}$ and $930^{\circ} \mathrm{C}$ ) followed by a dwell time of up to two hours. During the heat treatment, the glass particles sinter and bond with steel and electrolyte. The glass transforms into a glass-ceramic. After cooling down to room temperature with $5 \mathrm{~K} / \mathrm{min}$, cross sections of the sandwich samples are cut, polished and etched with HF to better distinguish the crystals from the glassy phase. The prepared cross sections are characterized by scanning electron microscopy (SEM; Zeiss Supra 35) and energy-dispersive X-Ray spectroscopy (EDS).

\subsection{Mechanical Characterization}

The mechanical testing of the sandwich sample is based on Charalambides four-point bending test [9, 10]. By using this test, the energy release rate during delamination of a thin layer on a substrate can be investigated. The necessary energy for delamination depends on the sample dimension, Young's modulus and the plateau value of the applied delamination force (Fig. 2).

To determine the influence of these parameters, two $5 \mathrm{~mm}$ broad glass ceramic films are screen-printed on substrates of Crofer $22 \mathrm{H}$ with a dimension of $45 \mathrm{~mm}$ length, $7 \mathrm{~mm}$ width and $2.5 \mathrm{~mm}$ thickness and sintered with two stiffeners $(22 \mathrm{~mm} \times 7 \mathrm{~mm} \times 2.5 \mathrm{~mm})$ on top as

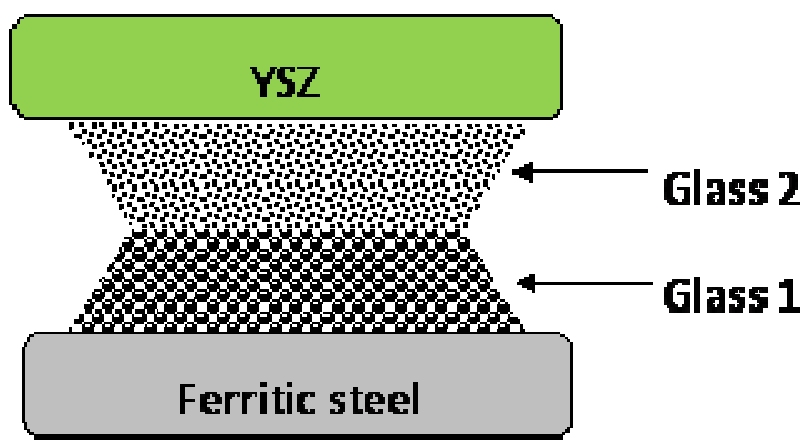

Fig. 1 Schematic setup of the sandwich sample with bilayered glass-ceramics.

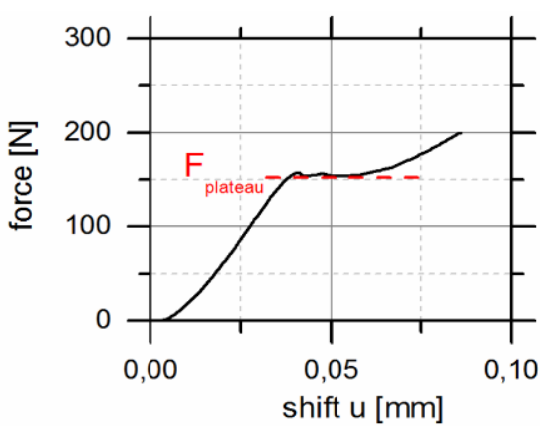

(a)

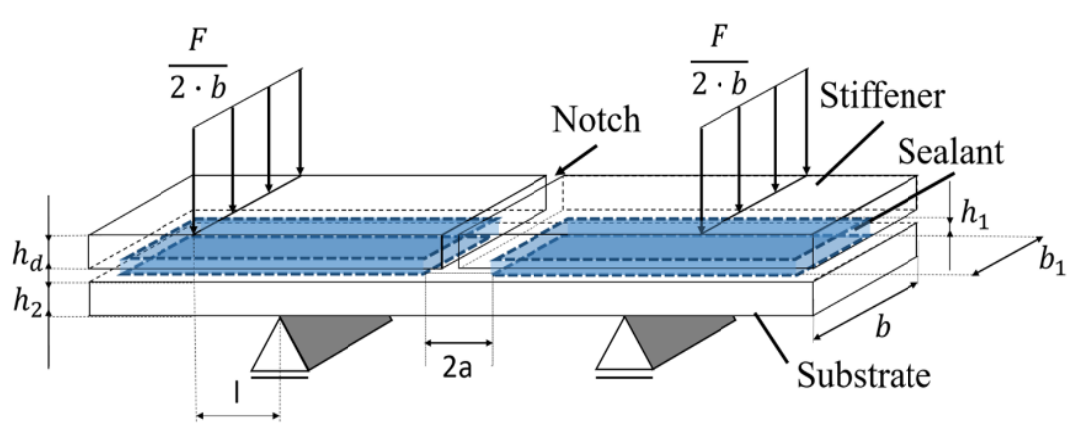

(b)

Fig. 2 (a) Force measurement during bending test and, (b) modified schematic setup of the four-point bending test according to Hofinger [10] with force $F$, substrate width $b$, width of printed film $b_{1}$, distance between printed films $a$, stiffener height $h_{\mathrm{d}}$, film thickness $h_{1}$ and substrate height $b_{2}$. 
previously described. The samples are tested in a four-point-bending fixture in a universal testing machine (UTS 10). The span ratio of outer and inner supports is $40 \mathrm{~mm}$ and $20 \mathrm{~mm}$, respectively. The sample bending is performed with a constant rate of $20 \mu \mathrm{m}$ per minute similar to Brandenberg et al. [12]. The necessary force for driving a crack forward is measured and exemplary shown in Fig. 2a. The mechanical test is interrupted, when a force above 200 $\mathrm{N}$ or a shift of $3 \mathrm{~mm}$ is reached. The measurements are evaluated and calculated according to Charalambides et al. [9] and Hofinger et al. [10].

\section{Results and Discussion}

\subsection{Properties of the Glass-Ceramics}

In total, two glass compositions were developed based on the patent DE 19857057 C1 by Ref. [16]. These are alkaline earth silicate glasses, the composition of which is listed in Chapter 2.1. Glass 2 additionally contains zirconium dioxide and yttrium oxide in the batch composition in order to improve the bonding to the 8YSZ and to prevent any possible dissolution of the electrolyte through the glass and excessive diffusion of elements at the interface [17].

During heat treatment at $900{ }^{\circ} \mathrm{C}$, Glass 1 and Glass 2 form spherical quartz-crystals $\left(\mathrm{SiO}_{2}\right)$ and enstatite-crystals $\left(\mathrm{Mg}_{2} \mathrm{Si}_{2} \mathrm{O}_{6}\right)$. EDS measurements have shown that sometimes small amounts of calcium

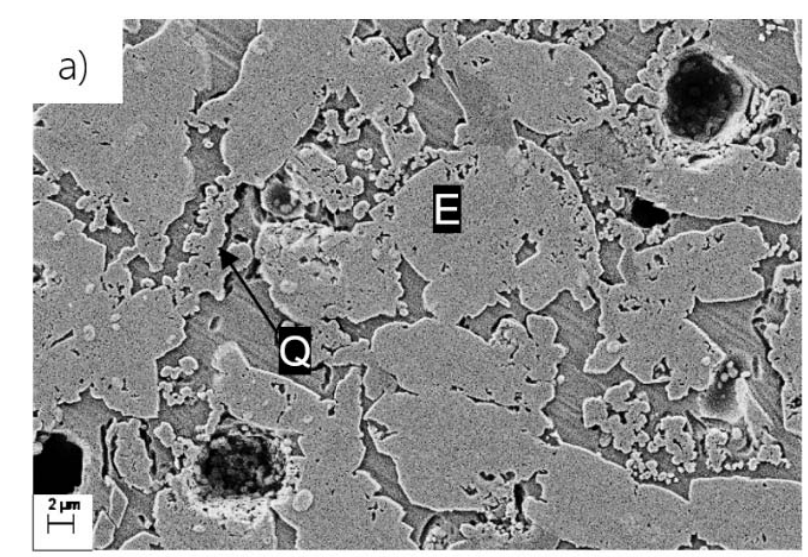

are incorporated in the enstatite, which partially replace the magnesium. Glass 2, which contains small amounts of $\mathrm{ZrO}_{2}$ and $\mathrm{Y}_{2} \mathrm{O}_{3}$, additionally forms baddeleyite-crystals $\left(\mathrm{ZrO}_{2}\right)$. Both glass-ceramics are presented in Fig. 3 and show a residual amorphous phase, which can make up to about 20 vol.\% for Glass 1 and up to 50 vol.\% for Glass 2.

The CTE of the glass sealant should be between the CTE of the interconnector $\left(11.8 \times 10^{-6} 1 / \mathrm{K}\right.$, RT- $\left.800^{\circ} \mathrm{C}\right)$ [15] and 8YSZ $\left(10.0 \times 10^{-6} 1 / \mathrm{K}, \mathrm{RT}-800{ }^{\circ} \mathrm{C}\right)$, which is a rather big difference that can cause mechanical stresses and lead to the formation of cracks within the sealant during manufacturing. Therefore, the CTEs of the two different glasses are determined. The thermal expansion coefficient is $11.0 \times 10^{-6} 1 / \mathrm{K}\left(\mathrm{RT}-500{ }^{\circ} \mathrm{C}\right)$ for Glass 1 , which is in the ideal range between the CTE of steel and 8YSZ. The CTE of Glass 2 is at first below the ideal value $\left(8.1 \times 10^{-6} 1 / \mathrm{K}\right.$, RT-500 $\left.{ }^{\circ} \mathrm{C}\right)$. But Glass 2 can still be used as the CTE increases significantly during operation of the SOFC due to progressive crystallization and approaches the CTE of the electrolyte. The crystallization of Glass 1 is almost completed after the first heat treatment of $900{ }^{\circ} \mathrm{C}$. Due to this fact, the CTE of Glass 1 hardly changes during longer heat treatments.

The thermo-optical measurements show that the pellets of Glass 1 retain their original shape even after heat treatment, only sintering takes place. This means

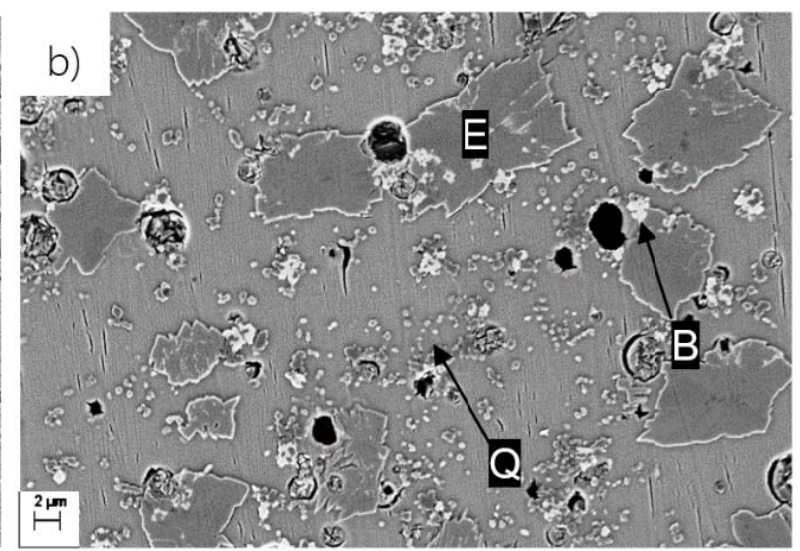

Fig. 3 SEM-images of the bulk microstructure of (a) Glass 1 and (b) Glass 2 (Q = Quarz, E = Enstatite, B = Baddeleyite). 
that the pellets volume decreases because of densification and reduction of the porosity but the shape remains identical (Fig. 4) [18]. The glass shows no activities of softening or viscous flow, which would result in rounded edges or even in the formation of a ball like shape of the former pellets. Glasses typically show viscous flow, which is not visible for this sample. Compared to Glass 2, a higher crystalline content and an earlier onset of crystallization (which are determined by SEM and $\mathrm{XRD)}$ are responsible for the absence of viscous flow.

The pellets of Glass 2 deform during the temperature treatment and get rounded edges. The glasses thus show not only sintering but also viscous flow behavior (Fig. 5). By applying a low weight to the pellets during temperature treatment, the sintering and viscous flow activities can be intensified. The sintering process of Glass 1 starts earlier and lasts longer while Glass 2 starts viscous flow activities at much lower temperatures and deforms into a flattened disc.

In addition, pellets of a combination of Glass 1 and Glass 2 are tested to investigate the interactions between them (Fig. 6). During heat treatment, Glass 1 again nearly retains its shape while Glass 2 starts to flow over it.

It seems that the good adhesion between the two glasses facilitates the sintering behavior. A larger shrinkage is recognized compared to the single glasses. Probably, crystalline phases can be easier formed at the interface and therefore a larger volume change is observed. This induces a higher densification at the interface which can result in differential sintering. This is visible through the narrowing of the pellet at the interface and through the delamination of Glass 1 from the substrate. Glass 2 adheres perfectly on Glass 1 ; it is not possible to separate them at the interface. The reaction of the two glasses at the interface is further investigated in Section 3.3.

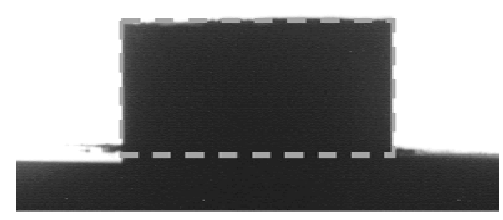

$10 \mathrm{~mm}$

(a)

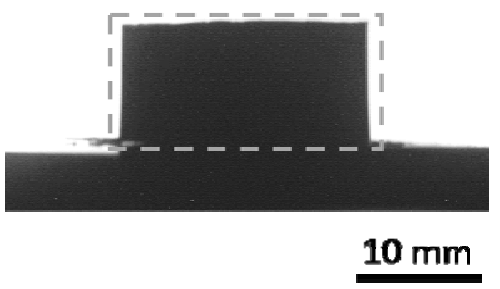

(b)

Fig. 4 TOM-images of Glass 1, (a) before heat treatment, (b) after heat treatment $\left(930{ }^{\circ} \mathrm{C}\right.$ for $2 \mathrm{~h}$ ).

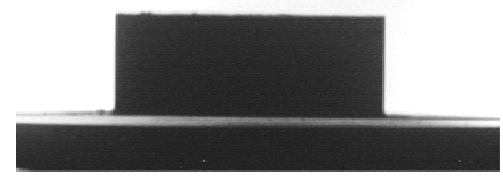

$10 \mathrm{~mm}$

(a)

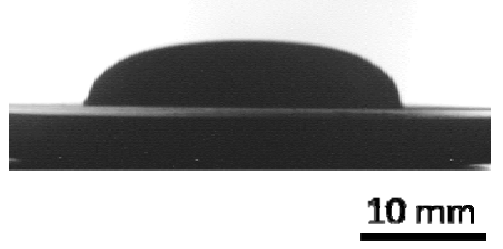

(b)

Fig. 5 TOM-images of Glass 2, (a) before heat treatment, (b) after heat treatment (930 ${ }^{\circ} \mathrm{C}$ for $2 \mathrm{~h}$ ). 


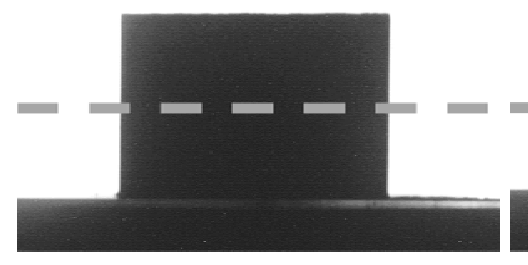

$10 \mathrm{~mm}$

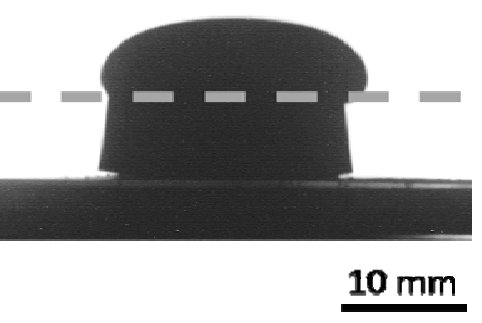

(b)

Fig. 6 TOM-images of Glass 1 and 2, (a) before heat treatment, (b) after heat treatment (930 ${ }^{\circ} \mathrm{C}$ for $2 \mathrm{~h}$ ).

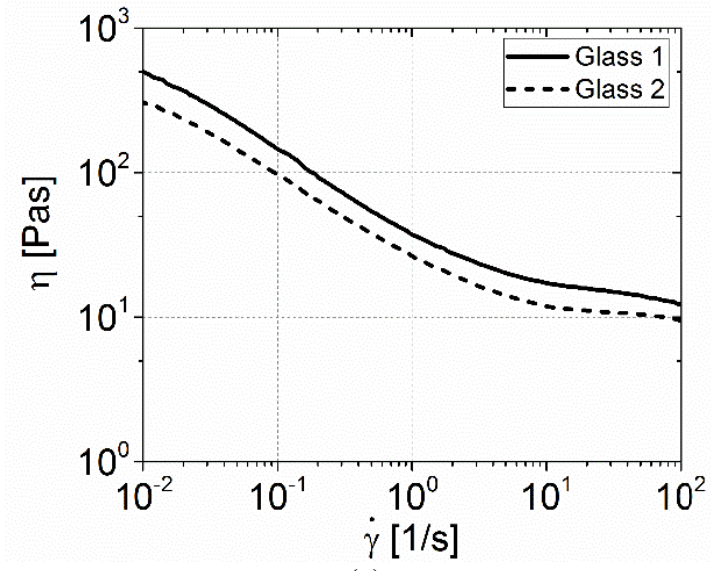

(a)

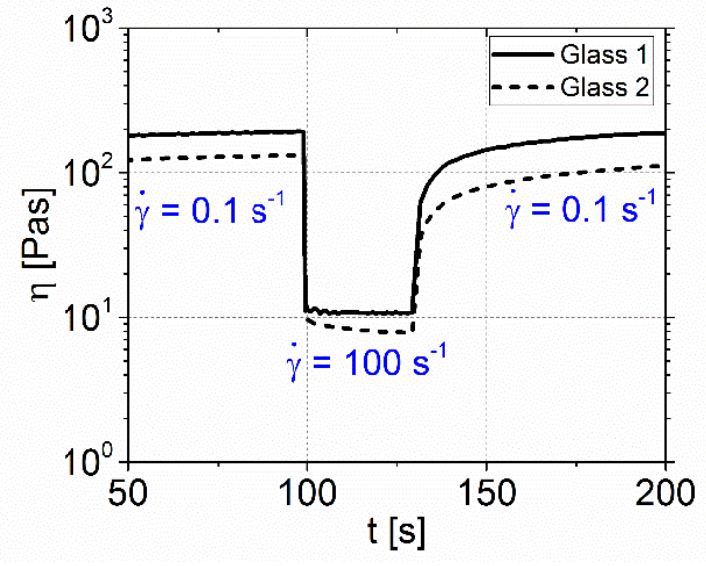

(b)

Fig. 7 (a) Flow curves and (b) recovery tests for Glass 1 and Glass 2 with a solid content of $58 \mathrm{vol. \% ,} 6 \mathrm{mg} / \mathrm{m}^{2} \mathrm{dispersing}$ agent and 10 vol.\% network agent.

\subsection{Rheology and Screen-Printing}

The flow properties of screen-printing pastes with Glass 1 and Glass 2 as ground powders are investigated, as depicted in Fig. 7. The pastes have a high solid content of approximately 60 vol.\%. In addition, $5-10 \mathrm{mg} / \mathrm{m}^{2}$ dispersing agent is used to improve the particle distribution and consequently reduce the viscosity. The addition of 5-15 vol.\% network agent allows better film levelling with low edge drift.

Shear-thinning and a corresponding low viscosity at high shear rates are favorable during the printing process, because the paste should easily flow through the screen mesh when the squeegee acts [19-21]. Both pastes show the same shear thinning behavior, the viscosity decreases more than one order of magnitude by increasing the shear rate from $0.01 \mathrm{~s}^{-1}$ to $100 \mathrm{~s}^{-1}$.
This strong change in viscosity is confirmed by the shear jumping test (Fig. 7b). By decreasing the shear rate to $0.1 \mathrm{~s}^{-1}$ again, the viscosity increases nearly to its initial value. This indicates that the paste regains its structure, levelling of irregularities in film thickness is possible and paste spreading on the substrate is avoided. Phair et al. [22] used shear jumping experiments to characterize the thixotropy behavior of concentrated zirconia inks at different shear rates and observed a comparable behavior. In order to verify the measured printing characteristics of the pastes, they were printed on $50 \mathrm{~mm}^{2}$ substrates with a small structure in the middle. The printed thick films of Glass 1 on ferritic steel and of Glass 2 on YSZ are reproducible and shown in Fig. 8. The layer thickness of both samples is about $160 \mu \mathrm{m}$ and the width of the larger contour is $3 \mathrm{~mm}$, which is the given mesh opening. According to these results, a sandwich of 
bilayered glass-ceramics consisting of Glass 1 and Glass 2 can be assembled.

\subsection{Composition and Microstructure of Bilayered Glass-Ceramics}

As mentioned in the previous section, the glass powders were deposited by screen-printing on ferritic steel and YSZ substrates. Then sandwich like structures were prepared to investigate the interfaces and the residual porosity of the sealants. The cross-sections of the following joined samples were examined by SEM:

- ferritic steel/Glass 1/ferritic steel (S/G1/S)

- 8YSZ/Glass 2/8YSZ (YSZ/G2/YSZ)
- ferritic steel/Glass 1/Glass 2/8YSZ (S/G1/G2/YSZ).

The S/G1/S joined sample was loaded with a weight of $120 \mathrm{kPa}$ during heat treatment at $900{ }^{\circ} \mathrm{C}$ for 2 h. In Fig. 9 the sintered film is shown, a few small pores are visible, but the gas-tightness is guaranteed. The glass-ceramic forms an enstatite layer at the interface to the ferritic steel, so the adhesion is excellent.

Glass 2 has a lower softening point and shows viscous flow behaviour. Therefore, the YSZ/G2/YSZ joined sample has a lower layer thickness $(d=50 \mu \mathrm{m})$ than Glass 1 for a load of $120 \mathrm{kPa}$ (Fig. 10). As described before, Glass 1 nearly retains its structure

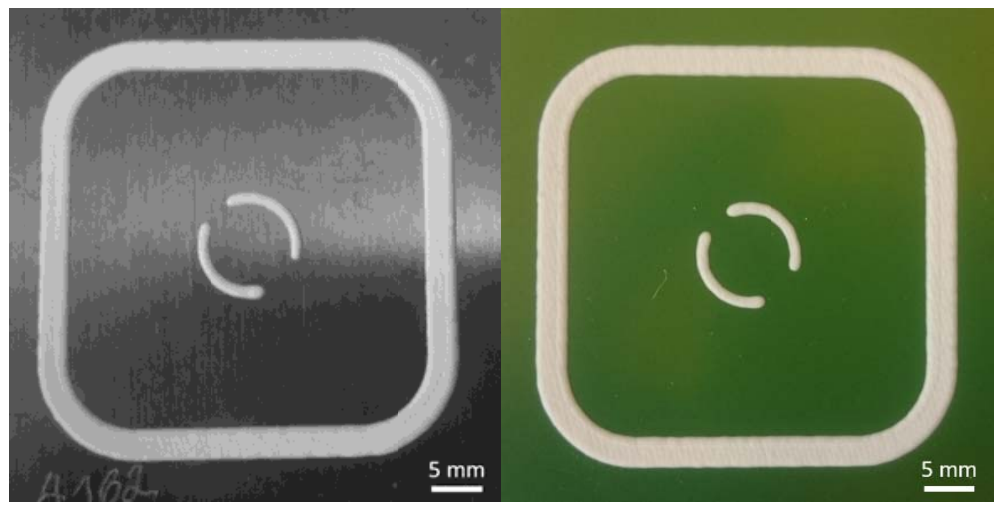

(a) (b)

Fig. 8 Printed films of (a) Glass 1 on ferritic steel and (b) Glass 2 on YSZ electrolyte. Solid content of $58 \mathrm{vol. \% ,6} \mathrm{mg/m²}$ dispersing agent and 10 vol.\% networking agent.

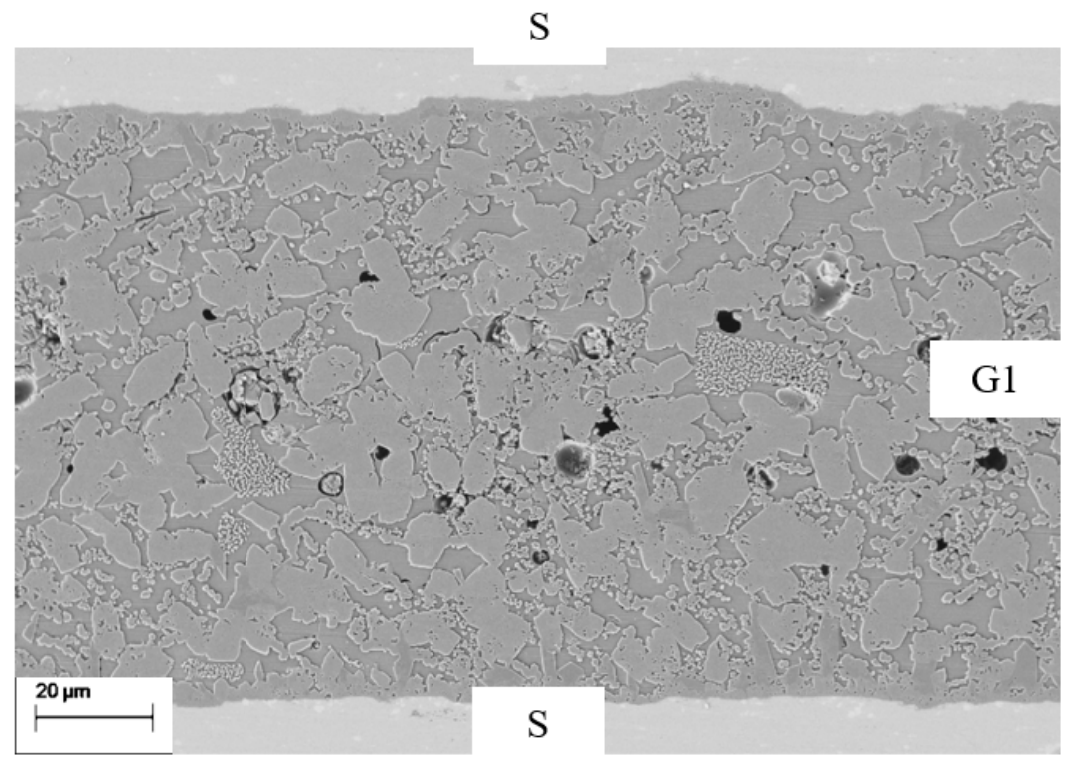

Fig. 9 SEM-image of sandwich sample S/G1/S, heat-treated at $900{ }^{\circ} \mathrm{C}$ for $2 \mathrm{~h}$. Applied load: $120 \mathrm{kPa}$. 


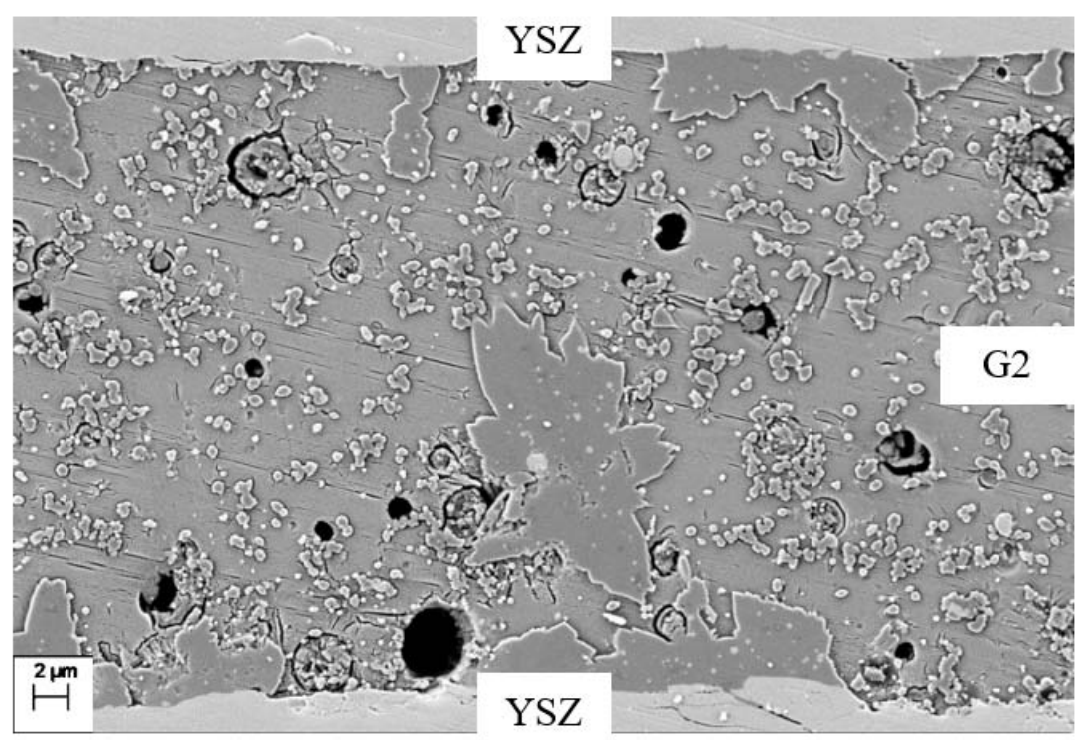

Fig. 10 SEM-image of sandwich sample YSZ/G2/YSZ, heat-treated at $900{ }^{\circ} \mathrm{C}$ for $2 \mathrm{~h}$. Applied load: $120 \mathrm{kPa}$.

and has a layer thickness of approximately $100 \mu \mathrm{m}$. The good adhesion of Glass 2 to the electrolyte probably results from the lower CTE and the addition of zirconium dioxide and yttrium oxide. A gap-free, flawless glass-ceramic layer was developed.

To improve the long-term stability of the glass-ceramic sealant and to avoid small cracks, which may result from the large CTE difference between ferritic steel and YSZ electrolyte, a sandwich sample of Glass 1 and Glass 2 was established. Fig. 11 shows an SEM-image of the bilayered glass-ceramics. For stability reasons, the order of the glasses in the TOM measurements was reversed compared to those in Fig. 11.

The sealing between steel and electrolyte seems to be excellent. A continuous glass-ceramic layer without cracks or delamination could be achieved. The two glass-ceramics do not mix completely. Due to their different microstructure, e.g. Baddeleyit crystals only being present in Glass 2, they can be clearly distinguished. The interface appears somewhat diffuse. EDS mappings clearly show that above all $\mathrm{Y}$ and $\mathrm{Zr}$ (which only occur in Glass 2) also diffuse beyond the interface into Glass 1. This correlates with the assumptions from the TOM measurements. Enstatite crystals form in both glasses regardless of the interface. Some pores appear in the glass-ceramics but they should not affect the gas tightness of the sealant. Mainly at the interface between the two glasses and near the YSZ electrolyte, it increasingly comes to pore formation. This occurrence of pores in the middle of the sample can be explained by the volume change during crystallization, because enstatite has a larger density than both glasses. It was investigated by SEM that the crystals start to grow at the interface to the substrates (in this case steel and YSZ) during heat treatment. The resultant pores migrate towards the amorphous glass phase, which is existent in the middle. This explanation shows that the pores are not induced by an interaction between Glass 1 and 2 .

\subsection{Mechanical Characterization}

The mechanical strength of three different sandwich samples is tested by four-point-bending method:

- ferritic steel/Glass 1/ferritic steel (S/G1/S)

- ferritic steel/Glass 2/ferritic steel (S/G2/S)

- ferritic steel/Glass 2/Glass 1/ferritic steel (S/G2/G1/S)

For the measurements, as substrates and stiffeners only ferritic steel is used. An experimental setup with 8YSZ as substrate is not suitable since $8 \mathrm{YSZ}$ shows a much lower energy release rate when fracturing than 


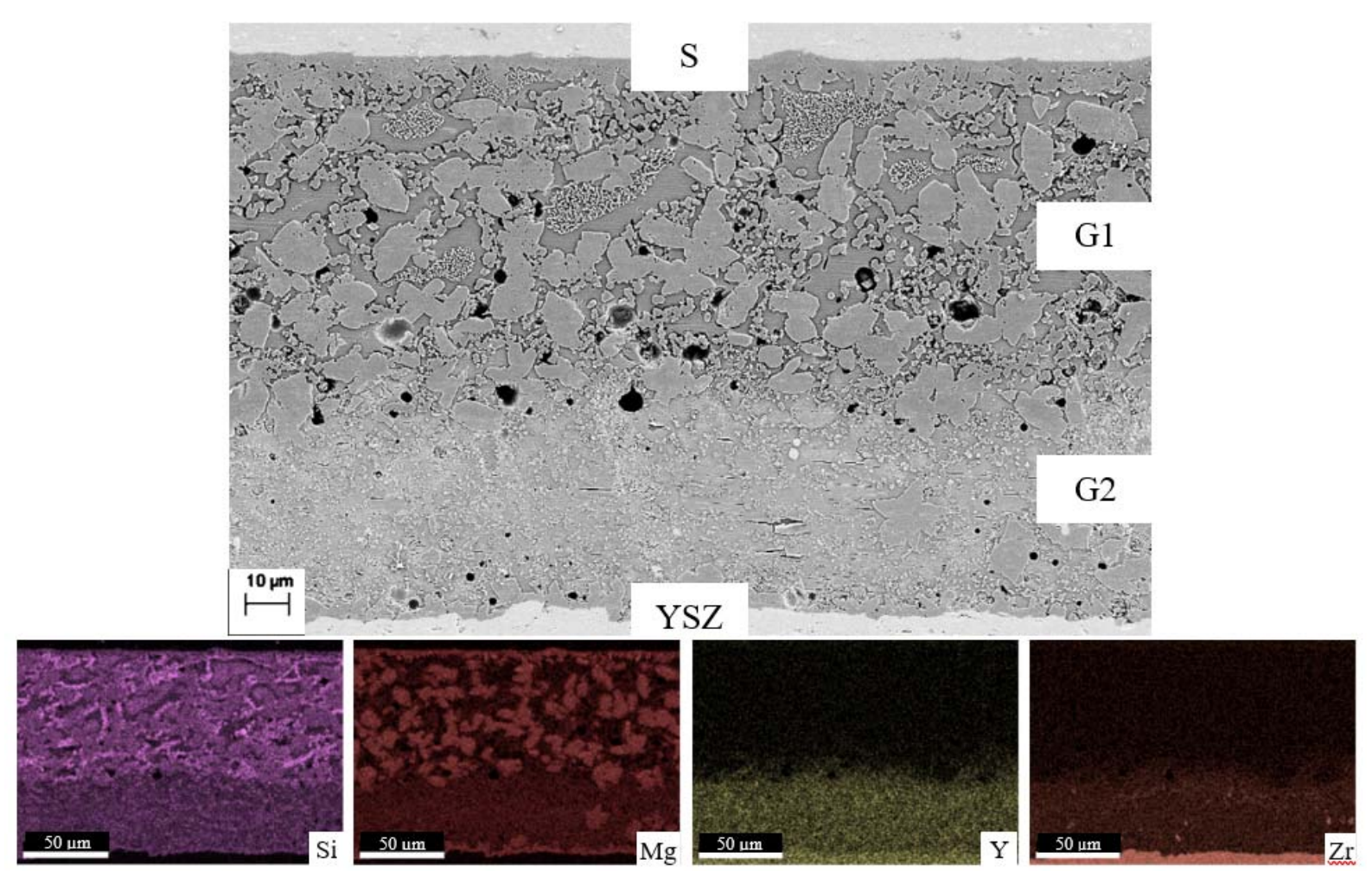

Fig. 11 SEM-image and EDS analysis of sandwich sample with bilayered glass-ceramics (S/G1/G2/YSZ), heat-treated at $900{ }^{\circ} \mathrm{C}$ for $2 \mathrm{~h}$. Applied load: $120 \mathrm{kPa}$.

the glass-ceramic sealant. For that reason, each introduced crack leaves the interface during testing. So, there is no delamination process measurable. The mechanical behavior of the different sandwich samples is described by the energy release rate $\left(G_{S S}\right)$, when a crack passes the interface, which is evaluated and calculated with the following Eq. (1) by Charalambides et al. [9] and Hofinger et al. [10].

$$
G_{S S}=\frac{M_{b}^{2}\left(1-v_{2}^{2}\right)}{2 E_{2}} \cdot\left(\frac{1}{I_{2}}-\frac{1}{I_{c}}\right)
$$

where $M_{b}$ is a constant bending moment, $v$ and $E$ describe the Poisson's ratio and the Young's modulus, $I_{2}$ and $I_{c}$ are the second moments of inertia.

If the energy release rate is high, a good adhesion is given and the delamination of the layer occurs at higher mechanical stress. For S/G1/S the sintering temperature and the applied load have no significant influence on the energy release rate (Figs. 12a and 12b). The rate remains constant at about $12 \mathrm{~N} / \mathrm{m}$. In contrast, an increase of the sintering temperature from
$860{ }^{\circ} \mathrm{C}$ to $930^{\circ} \mathrm{C}$ results in higher energy release rates up to $20 \mathrm{~N} / \mathrm{m}$ for S/G2/S (Fig. 12a). In addition, the dwell time is extended from $0 \mathrm{~h}$ to $2 \mathrm{~h}$; this induces a further increase of $G_{S S}$. The reason for this increment is attributed to a higher amount of crystalline phases in the material determined by SEM/EDS. For Glass 1 the formation of enstatite crystals starts at $850{ }^{\circ} \mathrm{C}$. At $880{ }^{\circ} \mathrm{C}$ in the middle of the sandwich sample and at the glass-ceramic-steel interface several crystals are visible. Due to this early appearance a plateau with constant energy release rate is reached at low temperatures.

Glass 2 shows a slightly different behavior. At temperatures below $880{ }^{\circ} \mathrm{C}$ no Enstatite crystals are formed. Therefore, the energy release rate is low with about $6 \mathrm{~N} / \mathrm{m}$ for $0 \mathrm{~h}$ and $10 \mathrm{~N} / \mathrm{m}$ for $2 \mathrm{~h}$. By increasing the temperature to $880{ }^{\circ} \mathrm{C}$ and by changing the dwell time from $0 \mathrm{~h}$ to $2 \mathrm{~h}$, more enstatite crystals are generated and they clearly improve the mechanical strength. At $900{ }^{\circ} \mathrm{C}$ and at a dwell time of $2 \mathrm{~h}$ the 


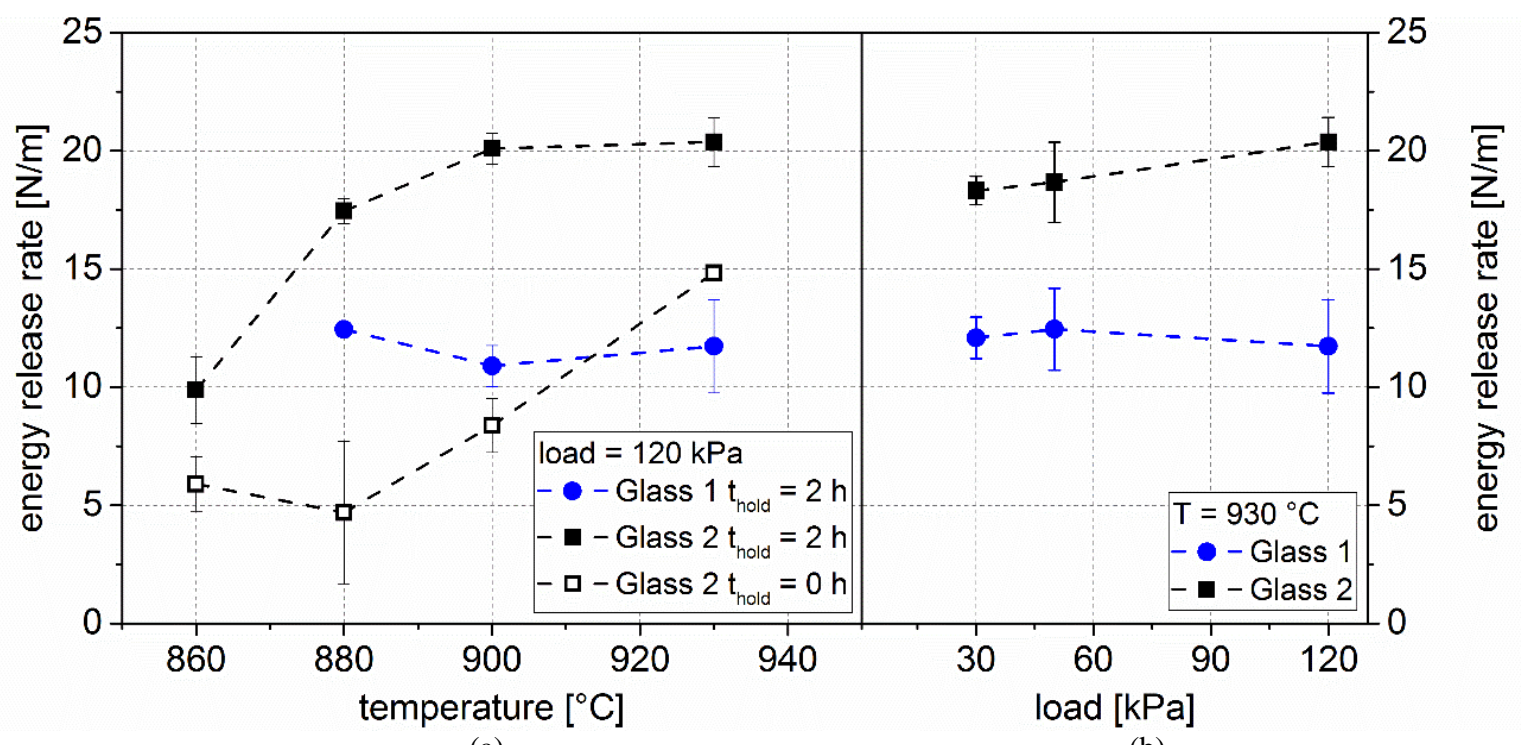

(a)

(b)

Fig. 12 Energy release rate of Glass 1 and Glass 20 ferritic steel and the dependence of energy release rates on (a) sintering temperature ( 860 to $\left.930{ }^{\circ} \mathrm{C}\right)$, dwelling time ( 0 and $2 \mathrm{~h}$ ) and (b) applied load (30 to $\left.120 \mathrm{kPa}\right)$.

Table 1 Layer width of Glass 1 and 2 before and after sintering at $930{ }^{\circ} \mathrm{C}$ with an applied load of $120 \mathrm{kPa}$.

\begin{tabular}{lll}
\hline & Layer width after screen-printing [mm] & Layer width after sintering [mm] \\
\hline Glass 1 & 5 & 4.5 \\
Glass 2 & 5 & 7 \\
\hline
\end{tabular}

plateau with constant energy release rate is obtained. A sufficiently long dwell time is important for the crystal formation and the resulting high mechanical strength of Glass 2.

Another important factor is the applied load on the sandwich sample. For S/G2/S the energy release rate slightly increases with higher sintering loads (Fig. 12b).

As mentioned before, Glass 2 shows more viscous flow behavior than Glass 1. This results in a larger layer width after sintering. The layer widths of Glass 1 and Glass 2 before and after sintering are listed in Table 1.

Therefore, the influence of the layer width on the energy release rate is investigated. Glass 1 is screen-printed on ferritic steel substrates with $2.5 \mathrm{~mm}$ and $5 \mathrm{~mm}$ layer width. These samples were heated up to $930{ }^{\circ} \mathrm{C}$ with a dwelling time of 2 hours and a load of $120 \mathrm{kPa}$. Afterwards, the energy release rate is calculated with Eq. (1). The $G_{s s}$-value of the film with half of the track width $(2.5 \mathrm{~mm})$ is approximately 6
$\mathrm{N} / \mathrm{m}$ and for the $5 \mathrm{~mm}$ layer it is about $12 \mathrm{~N} / \mathrm{m}$. This shows that the energy release rate is directly proportional to the track width. To get the same result for sealants with different track widths the equation ( $b$ = substrate width, $b_{1}=$ width of printed film, seen in Fig. 2) by Hofinger [10] for the energy release rate is adapted to:

$$
G_{s s_{\text {spec }}} \approx \frac{M_{b}^{2}\left(1-v_{2}^{2}\right)}{2 E_{2}} \cdot\left(\frac{1}{I_{2}}-\frac{1}{I_{c}}\right) \cdot \frac{b}{b_{1}}
$$

In comparison to Eq. (1), the change of the area moment of inertia is neglected.

According to these results, the values of the energy release rate presented in Fig. 12 are normalized to a specific width of $1 \mathrm{~mm}$ for both glasses as shown in Fig. 13. By considering the layer width, there is almost no difference between Glass 1 and Glass 2. At $930{ }^{\circ} \mathrm{C}$ they provide a normalized energy release rate of $2.5(\mathrm{~N} / \mathrm{m}) / \mathrm{mm}$. These results point out that both glasses have a similar good adhesion on ferritic steel. The difference in glass composition and the degree of crystallization have no significant influence on the 


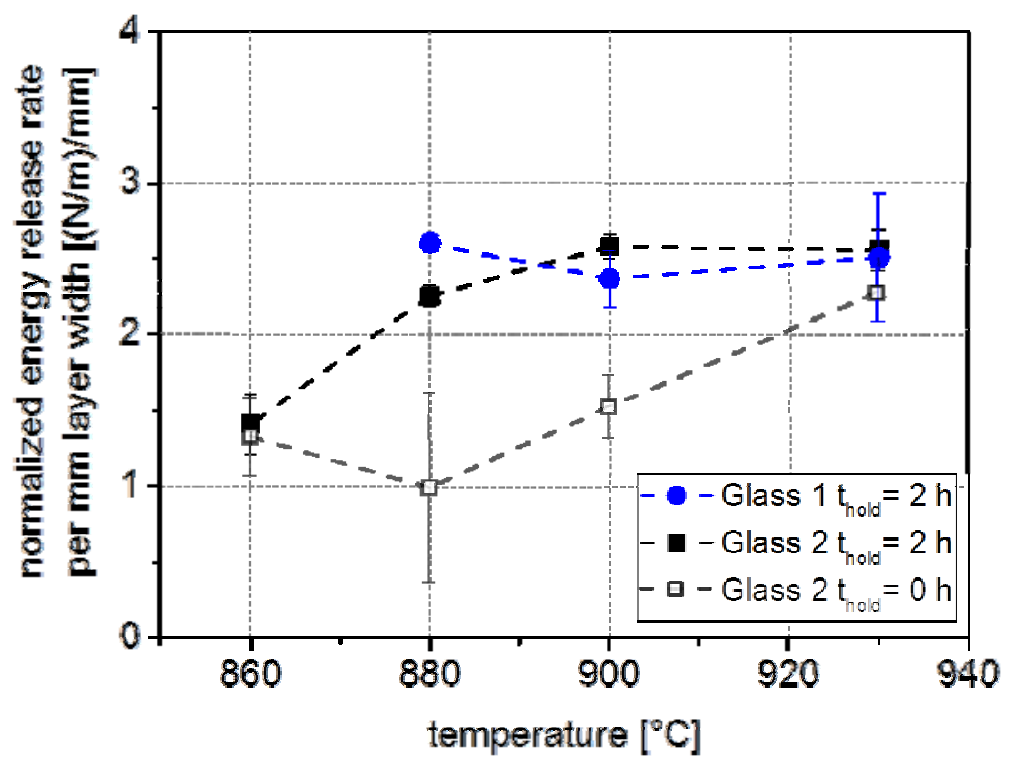

Fig. 13 Normalized energy release rate for Glass 1 and Glass 2 at different sintering temperatures and dwell times.
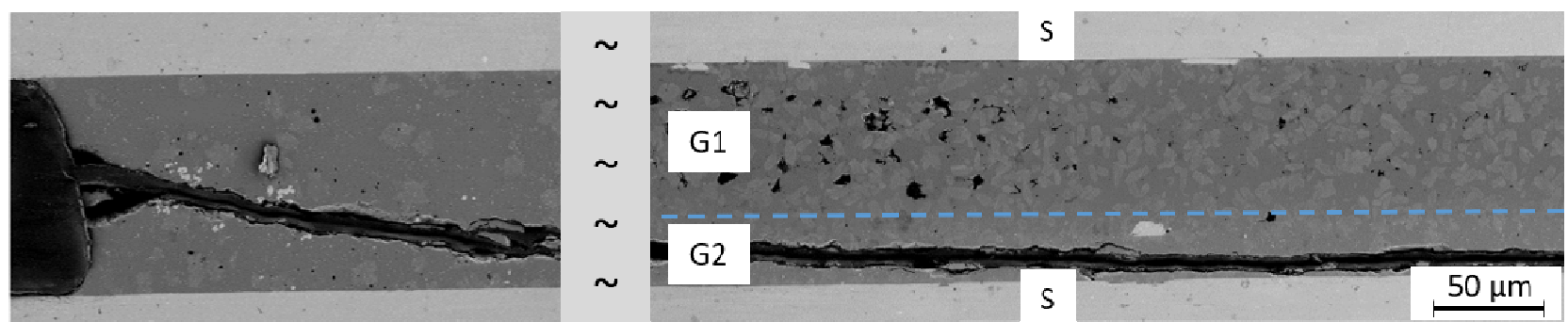

Fig. 14 SEM-Image of crack inlet and crack path for the bilayered glass-ceramic sealant between ferritic steel substrates.

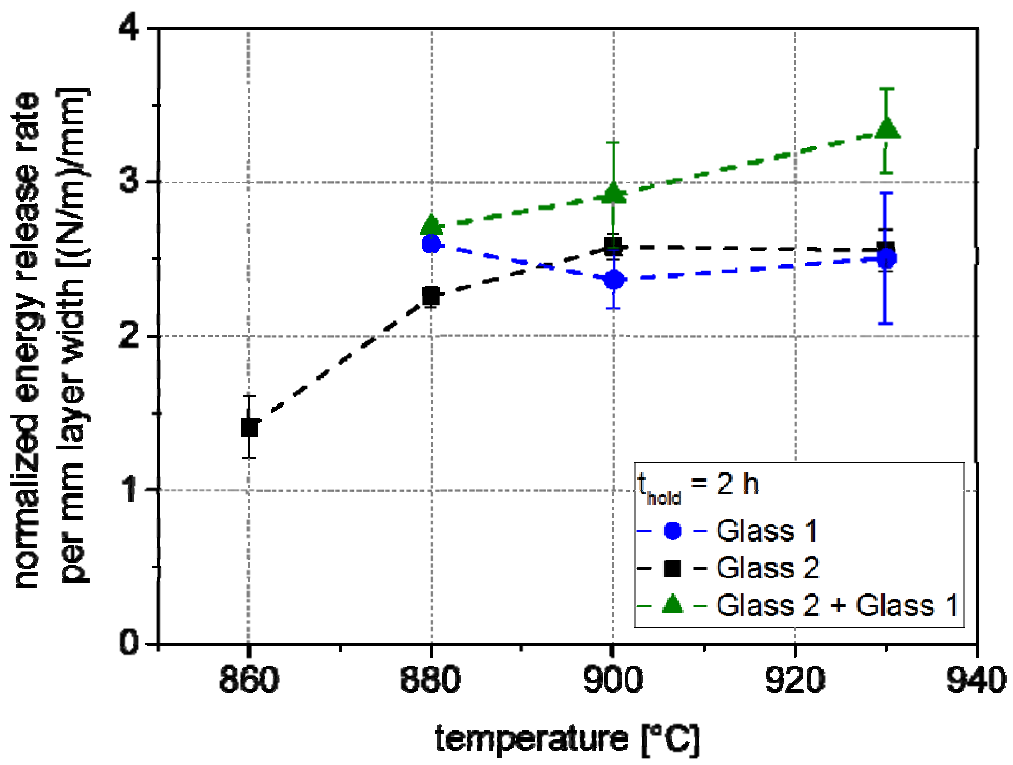

Fig. 15 Comparison of the normalized energy release rate for single and bilayered glass-ceramic sealants. 
normalized mechanical properties of the sealant.

In order to characterize the interface between the two glasses, mechanical tests are performed on the S/G2/G1/S sample. In addition, the cross-section of the mechanical tested sample is investigated by SEM, see Fig. 14. The mechanically introduced crack does not propagate along the G2-G1-interface, it passes through Glass 2 near the glass-steel interface. If the mechanical setup is turned around that the G2-layer is above the G1 layer, the crack would run through G1.

This result demonstrates the strong adhesion between the two glasses.

In Fig. 15, the normalized energy release rates of the single layers (S/G1/S and S/G2/S) are compared with the bilayered glass-ceramic (S/G2/G1/S). The normalized energy release rates of the bilayered glass-ceramic layers are in the range of $3(\mathrm{~N} / \mathrm{m}) / \mathrm{mm}$ for a sintering temperature of $900{ }^{\circ} \mathrm{C}$. This is slightly above the single glass-ceramic sealants and points out the good mechanical behaviour of the newly developed bilayered glass-ceramic. It seems that the interface between glass 1 and 2 offers, in addition to the two substrates, an area where crystalline phases can easily grow and thus improve the mechanical behaviour of the bilayered sample.

\section{Conclusion}

Bilayered glass-ceramics can fulfill all of the requirements for an SOFC sealant. Good adhesion on steel and electrolyte could be demonstrated by the continuous bonding of the glass-ceramics with the joining partners. By adjusted glass compositions and adapted manufacturing processes, samples without gaps and hardly any large pores could be obtained. The gas-tightness depends on the sintering and flowing behavior of the glasses/glass-ceramics and on the applied load during heat treatment. The thermal expansion coefficient of Glass 1 is in the ideal range between those of steel and electrolyte. Although the CTE of Glass 2 is slightly too low, a successfully joined sample can be achieved. The mechanical properties of sandwich samples were investigated by four-point bending tests. The energy release rate was measured and correlated to the sintering temperature, dwell time and load. A high amount of enstatite crystals results in a high mechanical strength and a better adhesion on ferritic steel substrates is given.

\section{Acknowledgements}

Financial support from Federal Ministry for Economic Affairs and Energy of Germany (BMWI No. 03ET6112A-C) is gratefully acknowledged. In addition, we would like to thank the Fraunhofer Institute for Nondestructive Testing (IZFP) for the good collaboration.

\section{References}

[1] 20180517-luftverschmutzung-klage_de@ec.europa.eu. 2018. https://ec.europa.eu/germany/news/20180517-luftversch mutzung-klage_de (accessed December 6, 2018).

[2] Larminie, J., and Dicks, A. 2003. Fuel Cell Systems Explained, 2nd ed. New York: Wiley. doi:10.1002/9781118878330.

[3] Stolten, D., and Emonts, B. 2012. Fuel Cell Science and Engineering-Materials, Processes, Systems and Technology, Vol. 1. Weinheim: Wiley-VCH.

[4] Töpfler, J., and Lehmann, J. 2017. Wasserstoff und Brennstoffzelle-Technologien und Marktperspektiven, 2nd ed. Berlin, Heidelberg: Springer Vieweg. doi:10.1007/978-3-662-53360-4.

[5] Kurzweil, P. 2016. Brennstoffzellentechnik—Grundlagen, Materialien, Anwendungen, Gaserzeugung, 3 ed. Wiesbaden: Springer Vieweg. doi:10.1007/978-3-658-14935-2.

[6] Kreuer, K.-D. 2013. Fuel Cells-Selected Entries from the Encyclopedia of Sustainability Science and Technology. New York: Springer. doi:10.1007/978-1-4614-5785-5.

[7] Fergus, J. W. 2005. "Sealants for Solid Oxide Fuel Cells.” J. Power Sources 147: 46-57. doi:10.1016/j.jpowsour.2005.05.002.

[8] Tietz, F. 1999. "Thermal Expansion of SOFC Materials.” Ionics (Kiel). 5: 129-39. doi:10.1007/BF02375916.

[9] Charalambides, P. G., Lund, J., Evans, A. G., and McMeeking, R. M. 1989. “A Test Specimen for Determining the Fracture Resistance of Bimaterial Interfaces.” J. Appl. Mech. 56: 77. doi:10.1115/1.3176069.

[10] Hofinger, I., Oechsner, M., Bahr, H. A., and Swain, M. V. 1998. "Modified Four-Point Bending Specimen for Determining the Interface Fracture Energy for Thin, 
Brittle Layers.” Int. J. Fract. 92: 213-20. doi:10.1023/A:1007530932726.

[11] Delette, G., Laurencin, J., Dupeux, M., and Doyer, J. B. 2008. "Measurement of the Fracture Energy at the Interface between Porous Cathode Layer and Electrolyte in Planar Solid Oxide Fuel Cells.” Scr. Mater. 59: 31-4. doi:10.1016/j.scriptamat.2008.02.018.

[12] Brandenberg, J., Kuhn, B., Pausch, M., and Beck, T. 2011. "Testing of Mechanical Performance of Reactive-Air-Brazed (RAB) Metal/Ceramic Joints for SOFC-Applications.” In 9th Eur. Fuel Cell Forum.

[13] Tucker, M. C., Dejonghe, L. C., García-Negrón, V., Trejo, R., and Lara-Curzio, E. 2013. "Mechanical and Electrochemical Performance of Composite Cathode Contact Materials for Solid Oxide Fuel Cells.” J. Power Sources 239: 315-20. doi:10.1016/j.jpowsour.2013.03.130.

[14] Xie, Y., Zhang, X., Robertson, M., Maric, R., and Ghosh, D. 2006. "Measurement of the Interface Adhesion of Solid Oxide Fuel Cells by Indentation.” J. Power Sources 162: 436-43. doi:10.1016/j.jpowsour.2006.07.034.

[15] ThyssenKrupp, Crofer 22H. 2008. Preliminary Material Data Sheet No. 4050.
[16] DE 19857057 C1, B. 2000. Durschang.

[17] Kaur, G., Pandey, O. P., and Singh, K. 2012. "Chemical Compatibility between $\mathrm{MgO}-\mathrm{SiO}_{2}-\mathrm{B}_{2} \mathrm{O}_{3}-\mathrm{La}_{2} \mathrm{O}_{3}$ Glass Sealant and Low, High Temperature Electrolytes for Solid Oxide Fuel Cell Applications.” Int. J. Hydrogen Energy 37: 17235-44. doi:10.1016/j.ijhydene.2012.08.067.

[18] Rahaman, M. N. 2008. Sintering of Ceramics, 1st ed., Boca Raton, FL: CRC Press. https://www.taylorfrancis.com/books/9781420007053.

[19] Yüce, C., and Willenbacher, N. 2017. “Challenges in Rheological Characterization of Highly Concentrated Suspensions-A Case Study for Screen-Printing Silver Pastes.” J. Vis. Exp. 122: 1-17. doi:10.3791/55377.

[20] Trease, R. E., and Dietz, R. L. 1972. "Rheology of Pastes in Thick-film Printing.” Solid State Technol. 11: 422.

[21] Riemer, D. E. 1989. "The Theoretical Fundamentals of the Screen Printing Process, Microelectron.” Int. An Int. J. 6: 8-17. doi:10.1108/eb044350.

[22] Phair, J. W., Lundberg, M., and Kaiser, A. 2009. "Leveling and Thixotropic Characteristics of Concentrated Zirconia Inks for Screen-Printing.” Rheol. Acta. 48: 121-33. doi:10.1007/s00397-008-0301-4. 